\title{
Inappropriate Circumstances for Laparoscopic Surgery
}

\author{
Atilla Şenaylı ${ }^{1}$ and Yeşim Şenaylı ${ }^{2}$ \\ ${ }^{1}$ Pediatric Surgery, T.C.S.B. Etlik İhtisas Education and Research Hospital \\ ${ }^{2}$ Anesthesiology and Reanimation, T.C.S.B. Health Education General Directorate \\ Turkey
}

\section{Introduction}

Laparoscopy is increasingly selected instead of the laparotomies at the last three decades. The earliest indications of laparoscopies were mostly for gynaecological treatments and cholecystectomies (Cunningham, 1998). Since then, spectrum has been expanding. Increasing laparoscopy experience caused expansion of the indications and, contrary to this, declining the contraindications. So, it can actually be accepted that, in the near future, there will be trace contraindications for laparoscopic procedures. Gastrointestinal operations, especially bowel obstruction treatments are attentive for this trend, thus increased surgical experience and improved surgical instrumentation changed opinions about the most emphasized contraindications for laparoscopic surgery (Reissman \& Spira, 2003). Consequently, surgeons who are willing to learn and develop their skills have to observe changes efficiently as laparoscopy indications, contraindications and risks definitions has been changing fast.

In a lot of studies, it was proved that surgeons' experience is the important factor for successful laparoscopies and many obstacles like laparoscopy-related complications, conversion rate, morbidity and mortality rates decreased with increasing experience (Tekkis et al, 2005). As Jansen et al explained, technical improvement and increasing experience in laparoscopy will probably continue to reduce the incidence of surgical complications (Jansen et al, 1997). Soot et al also reported significant decreases in the rates of the problems like conversions and they experienced that conversions rates changed from their first 25 patients to last 25 patients sharply in fundoplication cases (Soot et al, 1999).

Problems detected after gaining experience are usually the issues of technical problems and patient-related problems. Contraindications, in other words: not performing laparoscopy and conversions are main aspects of technical and patient related problem that interfere using laparoscopy or completing the laparoscopic attempts. We can easily put forward by evaluating the literature that contraindications will be minimized but if conversions are not focused on, the presence of this aspect may prevent authors from reaching successful laparoscopic results. Therefore, conversions must be evaluated in great attention. Conversion means changing laparoscopic procedure to open procedure because of intraoperative difficulties. Conversions, as mentioned above, can be related to experience but also to technical and patient's problems. Conversion is not a defeat but choosing the 
most appropriate way of treating the patient (Agresta et al, 2004). Simopoluos et al also considered the conversion as an alteration, not a failure, of the operative plan due to anatomic problems to avoid further complications (Simopoluos et al, 2005). In our opinion, conversions are not complications but should rather be considered as salvage for preventing more serious problems. Surgeons convert laparoscopies to prevent patients from possible injuries (Reissman \& Spira, 2003). If there is a doubt for safety and efficiency of the operative procedure, the surgeon should convert the procedure immediately to an open procedure (Cucinotta et al, 1998).

The entity, conversion, confused authors for laparoscopic operations. Thus, there are still controversies about performing laparoscopy for some conditions. These controversies are prolongation of the hospital stay and conversion related complications. From the patients' view, it can be said that they are disappointed with spending more time in hospital, facing complications related to conversion and consuming more money consequent to a laparoscopic operation converted to an open procedure. From the surgeons' view, conversions have not only been a failure in decision-making but also have been a disappointment and discouragement (Marusch et al, 2001). Significantly increased postoperative morbidity and mortality because of the conversions may be recognized for the disappointment of the surgeon (Marusch et al, 2001). Therefore, this situation forced surgeons through laparotomy particularly in private practice or in non-teaching hospitals which interrupt the expansions of the procedure (Dubuisson et al, 2001).

Delis et al stress that a correct preoperative decision making for operation style can only be made with preoperative prediction of postoperative morbidity for each patient (Delis et al, 2010). It was pointed out that knowing the variables associated with the risk of conversion would avoid wasteful laparoscopic attempts by proceeding directly to an open operation. (Simopoluos et al, 2005). Schmidt et al defined this entity as knowledge of the factors associated with success or failure of the laparoscopic approach and surgeon who has this knowledge will be cautious for preoperative preparation and counseling of patients (Schmidt et al, 2001).

According to all these considerations, conversions can be determined as perfect situations for a surgeon to face with patients' circumstance defining a real unsuitable factor for laparoscopy. Therefore, based on the above information, in our study, we expected to highlight the variable kind of situations forces surgeons to change their intraoperative plan and so, we try to structure a description for the inappropriate circumstances of the diseases for laparoscopy. For this, we evaluated conversions to find clues of predictive factors and to lighten surgeons for systematized decision-making of operations.

\section{Evaluation method for the conversions}

Some retrospective studies have already been taken their places in literature for predictability of conversions. For instance, Shen et al shared their experience with laparoscopic adrenalectomy to evaluate the reasons for conversion and to identify the high risk patients requiring conversion (Shen et al, 2004). We evaluated the English literature and detected a lot of articles mentioned about conversions. We focused on different types of articles like case reports, prospective and retrospective studies, reviews and meta-analysis. Among these reports we pay attention on complications, contraindications and especially on conversions. Our main purpose is to understand the operations that were converted to 
laparotomy and "Results" sections of the selected articles were especially evaluated. The situations of these patients figured out that patients could be operated with laparoscopy but for some reasons the operations were ended as laparotomies which meant that something interfere the surgeons' laparoscopy success. After the formation of this article subgroup, we sought for the reasons of conversions. Conversions occurred during the "laparoscopic approach", which meant to be at the very beginning of the operations, were excluded because they were usually caused by accidental processes like Veress needle accidents. Some conversions were because of the "laparoscopic techniques" which meant to be operating difficulties of the surgeon. Since surgeons' technical difficulty is a kind of personal subject, we also excluded this factor. As a result, we only evaluated the anatomical and physiopathological events that changed the way of surgery. Tekkis et al defined conversion reasons in three parts as patient-specific, procedure- specific and surgeon-specific factors (Tekkis et al, 2005). According to this classification, we can define that, we evaluate the patient-specific factors. Then, detailed reasons of conversions were tried to be found to put forward a solid definition of the conversion reason. As Schmidt et al clarified, by understanding the reasons for conversion, laparoscopic success may be improved via modifying standard preoperative medical management or using additional technological capabilities (Schmidt et al, 2001).

\section{Gall bladder operations}

Laparoscopic cholecystectomy is the most reported operation in literature for conversions. After developed in France, laparoscopic cholecystectomy expanded to United States in 1988 (Shea et al, 2004). Higher interest in the subject subsequently caused higher conversion rates at the beginning periods and because of the accumulated data conversions reasons can be evaluated more clearly (Shea et al, 2004). Yun et al determined the rates of conversion to open surgery in earlier studies as high as 10\% (Yun et al, 2010). After continuation the laparoscopic cholecystectomies conversion rates reduced to 3.3\% (Yun et al, 2010). It was defined that acceptable conversion rate for elective laparoscopic cholecystectomy is $3-5 \%$ and for emergent laparoscopic cholecystectomy because of acute cholecystitis is 6-35\% (Simopoluos et al, 2005). There is still a high rate of conversion for emergency cholecystectomies (Yun et al, 2010). Unfortunately, uniform definitions of the risk factors indicating conversion laparoscopic to open cholecystectomy have not been formulated by authors (Simopoluos et al, 2005). Karayiannakis et al defined the conversion criteria as risky adhesiolysis, inadequate exposure of operative field and definition problem for anatomy (Karayiannakis et al, 2004). In the meta-analysis of Shea et al, conversion reasons were figured out as dense adhesions, inflammation, common bile duct stones, acute cholecystitis and gangrenous gallbladder (Shea et al, 2004). They reported 1,400 patients for the conversion of 25,763 patients by evaluating 75 cholecystectomy articles in a meta-analysis and among these patients, dense adhesions $(n=290(\% 20.7))$, inflammation $(n=146(\% 10.4))$, common bile duct stones $(n=95(\% 6.8))$, acute cholecystitis $(n=96(\% 6.9))$ and gangrenous gallbladder $(n=15(\% 1.1)$ ) were operative problems for conversion (Shea et al, 2004). Cucinotta et al also introduced that adhesions and insufficiently visualized biliary anatomy were their main problem to perform conversion (Cucinotta et al, 1998). In Akyürek et al series, patients without a history of laparotomy had more conversions than the patients with histories of upper or lower laparotomies and the most reason was dense adhesion in Calot's 
triangle (4 patients), uncertain anatomy ( 2 patients), friable gallbladder ( 1 patient) and thick cystic duct 1 patient (Akyurek et al, 2005). Simopoluos et al also reported the inability to define the anatomy in Calot's triangle as the most common reason for conversion and among these patients $24(1.5 \%)$ had no inflammation and $46(16.9 \%)$ had an inflamed gallbladder (Simopoluos et al, 2005). In literature, two reports investigated the conversion reasons in details for laparoscopic cholecystectomy (Akyurek et al, 2005), (Simopoluos et al, 2005). Therefore, these literatures can be defined as two samples for throughout evaluation of predictors. Akyürek et al defined adhesions to decide the way of operation after entering the abdominal cavity and used 3-point grading system for this purpose (Akyurek et al, 2005). Grade 1 adhesions had filmy thickness, avascular, grade 2 had moderate thickness with limited vascularity and grade 3 adhesions had dense thickness with well vascularization (Akyurek et al, 2005). However, direct correlation between this grading score and conversions were not clear in this study (Akyurek et al, 2005). Simopoluos et al found male gender, previous upper abdominal surgery, higher age, diabetes and severity of inflammation were significant predictors for conversion. Male gender with 60 year-old age was a high predictor for conversion (Simopoluos et al, 2005). Degree of inflammation was predicted for the high rate of conversion (Simopoluos et al, 2005). Detailed data for the inflammation of the gall bladder were; elevated WBC count higher than $9000 / \mathrm{ml}$, fever higher than $37.5^{\circ} \mathrm{C}$, total bilirubin levels higher than $1.2 \mathrm{mg} / \mathrm{dl}$, aspartate transaminase higher than $60 \mathrm{U} / \mathrm{L}$, alanine transaminase $>60 \mathrm{U} / \mathrm{L}$ (Simopoluos et al, 2005).

In addition, Smith et al suggested ultrasonography for dilated common duct, choledocholithiasis and revealed a relative contraindication to laparoscopic cholecystectomy (Smith, 1992). Ultrasonographic evaluation could be expected to be leader for the evaluation of conversions but to our knowledge, a practical and definite usage of ultrasonography about the common duct and presence of choledocholithiasis predicting conversions has not been present in the literature.

\subsection{Gastrointestinal operations}

Laparoscopic procedures for intestinal diseases, especially for intestinal obstructions, have been under cautious evaluations and controversies have not been solved although progressive advantages were structured in laparoscopic treatment (Strickland, 1999). Collected information about conversion in this section was classified as anatomic definition or presentation related definition to ease the evaluation. Therefore, anatomic definitions are classified as stomach, duodenum, liver, pancreas, intestinal operations and presentation related definitions were classified as intestinal obstructions, abdominal trauma, obesity, diverticular, inflammatory diseases and tumoral diseases. Spleen is not evaluation in this section.

\subsubsection{Intestinal obstructions}

One of the reasons of controversies for acute abdomen may be originated from discouraging conversion rates. Chung et al reported $38.2 \%$ conversion rates for emergent laparoscopic surgery for acute abdomen (Chung et al, 1998). Wullstein \& Gross reported laparoscopic operations for small bowel obstruction and conversions were reported as high as (51.9 per cent) (Wullstein \& Gross, 2003). Suter et al reported 43\% conversion for their mechanical small bowel obstruction (Suter et al, 2000). Many authors estimated the operations for massive abdominal distension, the presence of peritonitis, highly inflamed bowel, 
hemodynamic instability, and severe comorbid conditions such as heart and lung diseases as contraindication for laparoscopic operations (Szomstein et al, 2006). As seen in intestinal obstructions, suspected adhesions guided surgeon for laparotomy because of the possibility of limited visualization and risk of bowel injury (Reissman \& Spira, 2003). Le Moine et al reported that patients with a known frozen abdomen must not be treated with laparoscopy and if laparoscopy was planned to be used in these patients needing emergent surgery (e.g., active hemorrhage, peritonitis, complete bowel obstruction) may be handle with great cautious (Le Moine et al, 2003). Chung et al mentioned about reasons for these conversions like advanced disease, uncontrollable fecal spill, forced exposure because of dense adhesions, debridement, abscess drainage, vascular surgery and hemodynamic deterioration (Chung et al, 1998). Obscured view due to intestinal distension with extensive adhesion and reduced field of the vision or perforations were the main reasons for conversion (Wullstein \& Gross, 2003), (Suter et al, 2000).

Suter et al recognized the usage of preoperative plain abdominal film showing a small bowel diameter exceeding $4 \mathrm{~cm}$ might be a predictive instrument for an increased risk of conversion (Suter et al, 2000). They reported that dilation of the intestinal loops reduced the working space as expected and increased intestinal fragility with distension might be correlated the plain abdominal graphy substantially (Suter et al, 2000). Conversion in these circumstances are not surprising, because the working space in the abdominal cavity is considerably shrank (Suter et al, 2000). On the other hand, they operate patients with laparoscopy even with a diameter exceeding $5 \mathrm{~cm}$ but conversion should not be underestimated if any difficulty was detected during the laparoscopy (Suter et al, 2000). Some authors classified the acute bowel obstructions for the availability of laparoscopic management (Reissman \& Spira, 2003). These criteria are proximal obstruction, partial obstruction, simple "single band" obstruction, and localized radiographic distension, no signs of systemic sepsis and mild abdominal distension (Reissman \& Spira, 2003).

\subsubsection{Abdominal trauma}

Trauma is in another main part of the argument for urgent laparoscopy and authors have different opinions for emergent surgery of trauma. Contraindications are defined as hemodynamic instability, known diaphragmatic injury, obvious intraabdominal injury, overt peritonitis or evidence of intraperitoneal penetration, posterior penetrating trauma with high likelihood of bowel injury (Villavicencio \& Aucar, 1999). Treatments for abdominal trauma with laparoscopy were defined as exploration of penetrating trauma in tangential gunshot wounds. It was pointed out that laparoscopy sensitivity for gastrointestinal injuries were as low as $18 \%$ but it might be used for the definition of the need of laparotomy (Villavicencio \& Aucar, 1999). However, Villavicencio et al defined the laparoscopy as a therapeutic tool for traumatic abdominal injuries. In their review of the studies, including 154 patients in 4 series, they showed that laparoscopy may be performed for at least $34 \%$ (53 patients) of the trauma patients treated with laparotomy (Villavicencio \& Aucar, 1999).

\subsubsection{Adhesions}

Adhesions lead dangerous separations of target organs and are the most seen circumstance for conversion (Schmidt et al, 2001). Le Moine et al reported that conversion related to adhesions and/or inflammatory pseudotumour was the major reason in their series and 21 
of the total 24 conversion patients had these problems (Le Moine et al, 2003). Agresta et al emphasized that the entity of unclear anatomy of adhesions were the most frequent causes of conversion (Agresta et al, 2004). As a result of previous operations, adhesions might be detected in next attempts and region of the previous surgery must be evaluated as a risk factor. Prior abdominal surgery caused inability to obtain adequate exposure for the critical region of interest and this is a predictor for open conversion and complications (Karayiannakis et al, 2004). Previous upper abdominal surgery caused 19\% conversion which was significantly higher than among those with previous lower abdominal surgery $(3.3 \%)$ and those without previous surgery (5.4\%) (Karayiannakis et al, 2004). Contrary to these opinions, Schmidt et al did not accept the number of prior abdominal procedures or the entity of previous abdominal surgery as a real predictor of conversion (Schmidt et al, 2001).

Some investigations were focused on the fact adhesion to make a classification. Tekkis et al classified their patients into three parts: patients with no adhesions, loose filmy adhesions that can be separated by blunt dissection and adhesions requiring up to $50 \%$ or more sharp dissection for separation with serosal injury or full-thickness injury. (Tekkis et al, 2005). Additionally, Karayiannakis et al reported about radiodiagnostic factors and offered using ultrasonography to explore the spontaneous or manual compression-induced visceral slide and to map the geography of dense intraperitoneal adhesions (Karayiannakis et al, 2004).

In various laparoscopic gastrointestinal operations, same predictive factors may be detected for conversions. For antireflux reoperations, Floch et al reported that adhesions were the most seen conversion reasons (4 patients in total 9 conversions) to the open procedure (Floch et al, 1999). Total conversion rate was $20 \%$ for other antireflux operation series. (Floch et al, 1999).

For colon operations, Schmidt et al reported that 44 of 110 patients (40\%) underwent 45 attempted laparoscopic procedures that were converted to open procedures. (Schmidt et al, 2001). This was the conversion rate of the patients who had prior colonic anastomosis and adhesions (Schmidt et al, 2001). Eighty percent of these converted patients were operated for segmental colonic resection and $78 \%$ of the conversions were needed during the lysis of the adhesion (Schmidt et al, 2001).

For appendectomies, Ball et al reported that performing laparoscopic operations became also impossible when extensive cecal adhesions were detected during appendectomy (Ball et al, 2004). Conversion to an open procedure was required for 10 patients because the appendix could not be mobilized after extensive cecal adhesions (Ball et al, 2004).

Adhesion in detailed investigation has not been reached in literature although it was figured out as a very important conversion factor. This may be because of the absence of diagnostic tools for the direct evaluation. Ultrasonography was used for evaluation in a study which can be accepted as an objective criterion. Therefore, we believe that systematized preoperative evaluation planning may be designed in the future.

\subsubsection{Obesity}

Obesity is one of the main problems for conversion. Different conversion rates were described in various operations for obese patient. Tekkis et al reported conversion risks were higher when body mass index was higher than 30. Additionally, conversion was significant if body mass index was greater than 50 (Tekkis et al, 2005). Patients undergoing conversion were significantly heavier (body mass index, 26.5) than those in whom the procedure was 
completed laparoscopically (body mass index, 24.9; P < 0.05) (Marusch et al, 2001). Conversion rates for laparoscopic colorectal surgery are $7 \%$ to $25 \%$ for larger series and $2 \%$ to $41 \%$ for smaller series (Tekkis et al, 2005). Tekkis et al reported conversion of obesity for colorectal surgery in 12 patients $(9.6 \%)$ in their series. In another report, Poddoubnyi et al defined that patients weighing more than $90 \mathrm{~kg}$ converted to open procedure up to $75 \%$ of the procedures and morbidity has been reported as 78\% (Poddoubnyi et al, 1998). Increased intraoperative complications related to higher conversion rates are not surprising for obese patients in laparoscopic colorectal surgery (Poddoubnyi et al, 1998). Massive obesity is also the reason of obstacle in reaching esophageal hiatus and caused conversion. (Higa et al, 2000) (Marusch et al, 2001). Chelala et al reported some of their patients who needed conversions because of difficult and risky dissection for their gastric banding operations (Chelala et al, 1997). Also they reported that left hepatic hypertrophy was risky for conversion causing four conversions to open procedure (Chelala et al, 1997). Subxyphoid ultrasonography was performed to evaluate hepatic hypertrophy for obese patients but significant correlation was not found (Chelala et al, 1997). Instead of this, early conversion determination was offered after introduction of the laparoscope and retraction of the liver to the right. (Chelala et al, 1997). Positioning the liver retractor more to the left of the xyphoid was reported to be the solution of conversion possibility.

\subsubsection{Intraabdominal tumor}

Curative laparoscopic surgery has still been investigating for gastrointestinal malignancies (Moreno et al, 1998). Tumor size and anatomical definition of the disease might be important for gastrointestinal operations. Excessive tumor bulk larger than 15 $\mathrm{cm}$ was defined to be an important factor for conversion (Tekkis et al, 2005). Marusch et al reported that medical situation of the patient has to be clarified for the size of tumor and intraoperative problems causing conversion would not be surprising if precautionary measures are not performed (Marusch et al, 2001), (Jaroszewski et al, 2004). Jaroszewski et al evaluated diagnostic tools for pancreatic tumors and showed that transabdominal ultrasonography(US) and computerized tomography(CT) is effective lower than $50 \%$ to $60 \%$ but spiral CT is more sensible (Jaroszewski et al, 2004). Magnetic resonance imaging has $45 \%$ to $91 \%$ success for insulinoma detection but endoscopic US is the most effective tool with preoperative detection rates of $86 \%$ to $93 \%$ (Jaroszewski et al, 2004). For insulinomas, invasive techniques such as percutaneous transhepatic venous sampling and arterial stimulation with venous sampling for insulin may be used but Laparoscopic Intraoperative US (LIOUS) gives excellent results for preoperative localization techniques(Jaroszewski et al, 2004). In spite of these technical possibilities if the tumor could not be identified accurately or vascular relations could not be seen effectively, conversion to open exploration should be considered (Jaroszewski et al, 2004). For colorectal tumor cases, Kwok et al reported 100 patients of colorectal carcinoma with colon or colorectal resection and experienced that phase 1 patients had higher conversion rates than phase 2 and rates were 33.3\% and 8.9\% respectively (Kwok et al, 1996). The important point of low conversion rates in phase 2 patients is the strict selection of the patients in this phase for laparoscopy and careful laboratory evaluations (Kwok et al, 1996). Careful selection of patients will reduce conversions and they pointed out that patient with bulky tumors, adjacent organ invasion with tumor or neighboring tissues has to be evaluated (Kwok et al, 1996). Also unexpected complications, intra-abdominal and 
abdominal wall tumor seeding are important for conversions (Moreno et al, 1998). For tumor operations, hemorrhage and perforations may be seen because of the adhesions of the tumor and therefore, Marusch et al warned surgeons for these adhesions (Marusch et al, 2001). Only pancreatic leakages had prolonged hospitalization after conversions and others conversion reasons had not important affects for hospitalizations according to completed laparoscopies. (Jaroszewski et al, 2004).

\subsubsection{Diverticular and inflammatory diseases}

Diverticular and inflammatory diseases can be the reason of conversion. Severity of diverticular disease provoke higher incidence of conversion (Marusch et al, 2001). Overall conversion rate was $7.2 \%$ but in less severe forms like peridiverticulitis, stenosis, or recurrent attacks of inflammation, conversion rates decrease to $4.8 \%$ and in severe forms like covered perforation, abscess, fistula, or bleeding, conversion was performed in $18.2 \%$ patients (Marusch et al, 2001), (Le Moine et al, 2003). Schmidt et al reported 58\% conversions for fistula (Schmidt et al, 2001). Tekkis et al had 37.6\% of conversion for inflammation and $13.6 \%$ of abscess/fistula caused conversions (Tekkis et al, 2005). Fistula (excluding enterocutaneous or perirectal fistulas) as an indication of surgery may cause conversion during laparoscopic procedure (Schmidt et al, 2001).

According to Le Moine et al, obesity was the only predictive factor for diverticular diseases in their experience but they added that attention had to be paid to the presence of sigmoid stenosis or fistula and severity of diverticulitis (Le Moine et al, 2003).

Crohn's disease with colonic (extracecal) subtype had a challenging technique caused by transmural inflammation and foreshortened mesentery makes things difficult (Schmidt et al, 2001). Additionally, patients with the colonic subtype of Crohn's disease appear in general to have a higher severity of disease, making them less amenable to laparoscopic approaches. (Schmidt et al, 2001). In Crohn's disease the degree of inflammation can be variable and unpredictable, which affects the technical complexity, surgical safety and laparoscopy success. (Schmidt et al, 2001). Presence of the Crohn's disease was not a predictor itself but disease severity and technical difficulty makes the difference for the conversion rates (Schmidt et al, 2001).

As smoking is known to exacerbate Crohn's disease, it was found to be significant for the association with conversion (Schmidt et al, 2001).

Colonoscopic evaluations may progress with complication resulting operations. Thus, colonoscopy may be a predictor. Hansen et al evaluated the patients resulted with laparoscopy after colonoscopic complications (Hansen et al, 2007). In three (27\%) cases conversion from exploratory laparoscopy to open laparotomy was performed and one of them had perforation appeared to be into the lesser omental bursa which was difficult to access, the other had perforation was deep in the pelvis (Hansen et al, 2007). Third case was converted for optimum management of a large segment of small bowel seen hyperemic and inflamed from fecal soilage. (Hansen et al, 2007). The mean perforation size causing conversion in their patients was $1.1 \mathrm{~cm}$ (range $0.2-2 \mathrm{~cm}$ ) but Hansen et al also added that conversion might be performed on the base of doubt of the repair security.(Hansen et al, 2007).

Laparoscopic biopsies for bowel lesions can cause conversions on an already weakened wall (Atchabahian et al, 1996). Atchabahian et al reported that they had an experience for Degos' 
disease and they offer not to perform biopsy for certain diagnosis (Atchabahian et al, 1996). Other reasons for conversion were the usage of steroid medication and preoperative malnutrition (Schmidt et al, 2001).

\subsubsection{Liver and pancreas diseases}

Surgeons are under pressure of the circumstances about the laparoscopic techniques for organs like liver or pancreas because of the presence of difficulty for retractions with current instrument, decision of resection margins and potential major injuries with neighboring tissues (Fong et al, 2000). Although there are difficulties, laparoscopic liver operations have begun in recent times. Cherqui et al was one of the leaders of laparoscopic liver operations and they reported 2 conversions among their 28 patients (Cherqui et al, 2000). First patient converted for hemorrhage originating from the neighboring tissue of the focal nodular hyperplasia and the other one converted because of the insufficient sight (Cherqui et al, 2000). Dagher et al reported conversion for seven patients (10\%) (Dagher et al, 2007). Diffuse bleeding during the parenchymal transection (3 patients) is the most important factor for conversion especially in segmental resections (Dagher et al, 2007). Exposure difficulties (2 patients: 1 segmentectomy $\mathrm{V}$ and 1 bisegmentectomy V-VI), unsatisfactory progression during parenchymal section (1 patient: trisegmentectomy V-VI-VII), and an anatomic variant of portal branches (1 patient: right hepatectomy) also caused other conversions (Dagher et al, 2007). On the other hand it was emphasized that only 2 patients were converted after the learning period (Dagher et al, 2007). Santambrogio et al used laparoscopic ultrasonography (LUS) to clarify the tumoral pathologies and only 2 patients were converted in their 15 patient series (Santambrogio et al, 2007). One of the patients had three lesions in segment 3 shown with LUS but bleeding from the adhesion between tumor and omentum caused conversion. The other patient had tumors near the portal pedicle of the left lobe caused an early conversion decision (Santambrogio et al, 2007).

Patients with pancreatic diseases reported by Jaroszewski showed that lesion in uncinate process of pancreas adjacent to superior mesenteric vein may cause conversion (Jaroszewski et al, 2004). Jaroszewski et al offered laparoscopic intraoperative ultrasonography (LIOUS) for decision-making (Jaroszewski et al, 2004). However, it can be unsuccessful and conversion may need as experienced in one of their patient (Jaroszewski et al, 2004).

\subsubsection{Duodenal diseases}

Treatments for duodenal diseases with laparoscopic procedures were defined. Duodenal perforations were repaired by laparoscopy and only five (17\%) patients underwent conversion to an open procedure (Kathouda et al, 1996). Large perforations (diameter 6 $\mathrm{mm}$ ) were reported to be the reasons for conversion in 3 patients. Additionally, beginning time of the symptoms was defined to be significant for conversion and if the symptoms began for more than 24 hours conversion rate detected $33 \%$ of the patients (Kathouda et al, 1996). Conversion rates were $0 \%$ when symptoms began less than 24 hours (Kathouda et al, 1996).

\subsubsection{Stomach operations}

Difficult dissections of posterior esophagus, identification problem of left diaphragmatic crus and hemorrhage are the main reasons of conversion during laparoscopic 
fundoplication but obstacle in the view is the most important factor for experienced surgeons (Soot et al, 1999).

Laparoscopy was also used for pyloromyotomy and conversions were reported. Sitsen et al reported 3 patients with mucosal perforation with laparoscopy which converted to transverse right upper quadrant minilaparotomy (Sitsen et al, 1998). For pyloromyotomy, prolongation of hospital stay was not significant after conversions (Sitsen et al, 1998).

For laparoscopic gastric ulcer treatments, Siu et al reported $21.5 \%$ conversion rate (Siu et al, 2004). Agresta et al reported conversion rate as $12 \%$ for their operated 51 patients because of inadequate ulcer localization (Agresta et al, 2004). Ulcer perforations larger than $10 \mathrm{~mm}$ and nonjuxtapyloric gastric ulcers were the main group of conversion but there were patients converted for technical difficulties and unidentifiable perforations (Siu et al, 2004).

Higa et al reported hepatomegaly as an important risk factor for the conversions of gastric operations (Higa et al, 2000). Huge liver interfere the operation sight especially for esophageal hiatus procedures. Therefore, performing safe dissections are challenging (Higa et al, 2000). Additionally small abdominal cavity was determined to be a risk for conversion (Higa et al, 2000). Some patients with past abdominoplasty caused the inability to establish an adequate pneumoperitoneum preventing safe dissection and visualization (Higa et al, 2000).

\subsubsection{Intestinal operations}

Laparoscopic treatment of invagination reduction was evaluated and $22.4 \%$ reduction failure revealed during endoscopic treatments which lead to open procedure (Poddoubnyi et al, 1998). Most conversions in this report were seen for ileoileocecocolonic invaginations (8 in 22 cases) but ileoileal, ileocecal and ileocecocolonic invaginations were reported also (Poddoubnyi et al, 1998).

One the most performed laparoscopic procedure for intestinal treatments was laparoscopic appendectomy. So et al reported $47 \%$ of conversions which was correlated with inexperience (So et al, 2002). It was reported that at least 20 cases had to be operated for optimum laparoscopy knowledge (So et al, 2002). Difficulty of dissection is the main reason of conversion and also unclear anatomy, appendicle mass and inadequate working space for appendectomy (So et al, 2002). Mucinous appendicieal tumor is important for laparoscopic appendectomies and special effort has to be spent while grasping the tissue. Appendiceal malignancies were reported to be evaluated earlier to prevent the patient from seeding of the tumor (Moreno et al, 1998). Another aspect that has to be kept in mind to prevent from conversion is retrocecal location of the appendix (Moreno et al, 1998).

\section{Spleen operations}

Conversion rates in laparoscopic splenectomies were reported as $0 \%$ to $19 \%$ in different studies (Brody et al, 1999), (Kathouda et al, 1996). Performing laparoscopic splenectomy was considered to be a contraindication at first, but soon, especially for enlarged spleens, diseases involving spleen were managed successfully by laparoscopy (Targarona et al, 1998). Although the main argument for conversions has been originated from the weight of the spleen, there have been controversies related to conversions caused by splenic weight. Targarona et al reported in their series that conversions occurred because of splenomegaly, weighing $2500 \mathrm{~g}$ to $3500 \mathrm{~g}$ for the patients with spherocytosis and non- 
Hodgkin's lymphoma (Targarona et al, 1998). For the enlarged spleen weighing as much as $2500 \mathrm{~g}$, they foresaw that it would be difficult to obtain enough intraabdominal space to manipulate the spleen (Targarona et al, 1998). Mahon \& Rhodes reported that their 6 patients among the 39 operated splenectomies were converted to open procedure whose wet spleen weights were more than $1 \mathrm{~kg}$ (Mahon \& Rhodes, 2003). However, Glasgow \& Mulvihill pointed out that the weight was not important and reported successful laparoscopies of the patients who had spleen weighting over than $3890 \mathrm{~g}$ (Glasgow \& Mulvihill, 1997). According to Katkhouda et al lymphoproliferative disease could be recognized as having high conversion rate and spleen weight over $3800 \mathrm{~g}$ has to be taken into account for conversion in spite of controversy is present (Kathouda et al, 1996). They converted 4 patients because of this reason. At the beginning of their practice Kathkhouda et al used preoperative CT scan or ultrasound in defining the spleen size but later they abandoned this procedure because they revealed size dependent decision-making useless in their practice except the patients with ITP or gallstones in patients with hemolytic anemia (Kathouda et al, 1996). Therefore, we summarize these variable informations as laparoscopic splenectomy for the spleen weight higher than $2500 \mathrm{~g}$ may be performed in great cautious and in any period of laparoscopy, if difficulty begins, conversions must be performed.

Bleeding may be another obstacle for laparoscopic splenectomy. Targarona et al reported conversions in 2 patients caused by diffuse oozing and difficulty in handling the spleen related to idiopathic thrombocytopenic purpura and AIDS-related thrombocytopenia (Targarona et al, 1998). Bleeding was the main reason for Glasgow et al and six patients converted for this reason (Glasgow \& Mulvihill, 1997). They reported the first 4 patients in their beginning period of the practice and the last 2 were in experienced periods (Glasgow \& Mulvihill, 1997). They emphasized that converted patients did not have previous abdominal surgery (Glasgow \& Mulvihill, 1997). Katkhouda et al reported that three patients converted for bleeding (Kathouda et al, 1996). They found conversion rates for lymphoproliferative diseases higher than idiopathic thrombocytopenic purpura (Kathouda et al, 1996). Katkhouda et al reported the hemorrhage during hilar dissection as a conversion reason in $3 \%$ of their patients (Kathouda et al, 1996).

Densely adherent abdominal structures to the spleen are one of the reasons of conversions of laparoscopic splenectomies (Brody et al, 1999). Brody et al reported one of the patients in their series with adhesive omentum on the spleen without prior operation history which was the cause of the tears as the reasons of laparotomy (Brody et al, 1999). Also splenectomy of a patient with pancreatitis had adherent pancreatic tail to the splenic hilum required conversion in their series (Brody et al, 1999). They additionally reported that after handled with experience this would not be a problem (Brody et al, 1999).

Katkhouda et al reported that splenectomies for trauma were excluded for laparoscopic procedure and in their series laparoscopies did not have priority for malignancy diagnosis (Kathouda et al, 1996).

Predictive factors are not clarified in details for laparoscopic splenectomy. Acute and/or traumatic reasons are generally accepted as the reasons of laparotomy. Bleeding and adhesions are preoperative problems that have to be recognized during the procedure but preoperative predictability is not strong enough for decision-making. Although best evaluations are focused on the weight of the spleen, defining a precise prediction is not easy even for weight measuring with these findings yet. 


\section{Gynaecological operations}

Risk factors for gynaecological operations are not different from other operation types. Chi et al reported that laparoscopic procedures were converted to laparotomy for 3 reasons; complications during the laparoscopy, technical difficulty and change in the planned treatment of malignancy (Chi et al, 2004). Some reported predictors are obesity, previous laparotomy, coexisting medical conditions, anticoagulant use (Jansen et al, 1997). Jansen et al reported 13 of 47 patients $(11.8 \%)$ converted to laparotomy because of previous operations which were the most frequently encountered association for conversion (Jansen et al, 1997).

Severe pelvic inflammatory disease and adhesions obliterating the cul-de-sac that may cause bowel perforation possibility is a risk factor for transfundal laparoscopy (Santala et al, 1999). Chi et al also reported adhesion as a predictive factor and defined the previous abdominal surgeries causing poor visualizations with dense adhesion (Chi et al, 2004). Walker et al reported 434 converted patients $(25.8 \%)$ in their large series and the most seen reason for conversion was poor exposure in 246 patients (14.6\%) (Walker et al, 2009). Also, cancer was found to be an important factor affecting 69 patients $(4.1 \%)$ for conversion (Walker et al, 2009). Excessive bleeding was cited as the reason for conversion in 49 patients $(2.9 \%)$ (Walker et al, 2009). Body mass index (BMI) was also reported to be important and a concordance was defined with the increasing conversion percentage and BMI (Walker et al, 2009). BMI of $25 \mathrm{~kg} / \mathrm{m} 2$ had $17.5 \%$ conversion rate, BMI to $35 \mathrm{~kg} / \mathrm{m} 2$ had $26.5 \%$ conversion rate and BMI with greater than $40 \mathrm{~kg} / \mathrm{m} 2$ had $57.1 \%$ conversion rates (Walker et al, 2009).

Laparoscopic myomectomy is investigated for conversions. Conversion incidence for myomectomy varies in a spectrum from $10.7 \%$ to $41.4 \%$ (Dubuisson et al, 2001). Although subserous and intramural myomas has been treated by large number of teams, the technique is difficult, time consuming, and involve a high risk of conversion to laparotomy (Dubuisson et al, 2001). Dubuisson et al experienced that most of the patients converted to laparotomy were related to cleavage problem and suturing difficulty (Dubuisson et al, 2001). To prevent patient from this, Dubuisson et al used US examination and size at US, intramural type, anterior location of the biggest myoma were defined to be useful (Dubuisson et al, 2001). They reported that intramural myoma, anterior myoma and myoma larger than $50 \mathrm{~mm}$ had a higher risk for conversion (Dubuisson et al, 2001). Conversion of the intramural myoma, especially big myomas, depended on the difficulty of suturing the deep hysterotomy (Dubuisson et al, 2001). As a laboratory entity, although there is a controversy for this subject, preoperative usage of $\mathrm{GnRH}$ agonist, independent from the duration or dosage, is found to be a predictive factor for conversion (Dubuisson et al, 2001).

Dubuisson et al reported that systematic research for adenomyosis had to be performed and US had to be used cautiously before the operations (Dubuisson et al, 2001). Malignancy does not have a definitive surgical treatment modality for either laparoscopy or laparotomy (Sagiv et al, 2005). After the frozen section, immediate decision has to be made to complete the operation (Sagiv et al, 2005). If the laparoscopic ovarian cystectomy is performed, cyst size does not affect the plan even for the huge cyst size (Sagiv et al, 2005).

\section{Retroperitoneal and urologic operations}

The use of laparoscopy in urologic surgery has gained attention since 1990 (Mendoza et al, 1996). Authors evaluating the urologic and retroperitoneal laparoscopic operations reported 
different opinions. For instance, Fergany et al put forward that patients with multiple previous abdominal surgeries, acute intraperitoneal infectious problems and uncorrected bleeding diatheses should not be operated (Fergany et al, 2000). Mendoza et al performed 1,022 different urologic laparoscopic procedures and they converted 15 patients (Mendoza et al, 1996). These conversions were due to either suboptimal visualization, difficulty with dissection from scar tissue, excessive obesity, or bleeding (Mendoza et al, 1996). Esposito defined another perspective for conversion of retroperitoneal diseases and reported that endo- and retroperitoneal vessel lesions generally require immediate conversion which was different from endoabdominal vessels (Esposito et al, 1997).

\subsection{Nephrectomy}

Nephrectomy with laparoscopy has advantages according to laparotomy but when conversion performed hospital stays and complications increases. Keeley \& Tolley reported that their converted patients had a longer operative duration and length of stay in hospital (Keeley \& Tolley, 1998). Complication rate for both laparoscopic nephrectomy (17.5\%) and nephroureterectomy $(18 \%)$ was found to be similar in their series including the patients with inflammatory conditions such as pyonephrosis, staghorn calculi, xantogranulomatous pyelonephritis (Keeley \& Tolley, 1998). Keeley \& Tolley converted five cases to open surgery; four for failure to progress (two with staghorn calculi / pyonephrosis, one with locally advanced transitional cell carcinoma and one with xantogranulomatous pyelonephritis), and one to remove a large policyctic kidney (Keeley \& Tolley, 1998).

Partial nephrectomy with laparoscopy is more difficult than total nephrectomy and needs more experience. Possible renal and extrarenal complications can cause more conversion (ElGhonemi et al, 2003). ElGhonemi et al reported that they converted 4 patients because of difficulties in completing anastomosis, two converted for kidney rotation and one had a huge pelvis (ElGhonemi et al, 2003). According to ElGhonemi et al significant peritoneal tear causes leak of the gas and this problem was also a conversion reason and one patient was converted to open surgery (ElGhonemi et al, 2003).

Matın added that the presence of any ureteric tumour is a contraindication to laparoscopic nefroureterectomy (Matın, 2005).

\subsection{Prostatectomy}

Bhayani et al used laparoscopy for prostatic treatments and converted 13 patients $(1.9 \%)$ to open procedure (Bhayani et al, 2004). Four of their patients had dense adhesions, 2 patients had obesity BMI greater than 30 and one patient for inadequate tumor resection at the bladder neck (Bhayani et al, 2004). Periprostatic scarring and cleavage problems were the main reason of conversion (Bhayani et al, 2004). Bhayani et al added that patients with markedly enlarged prostate and patients treated with androgenic deprivation therapy should not be operated with laparoscopy (Bhayani et al, 2004).

\subsection{Adrenalectomy}

Adrenalectomy has been one of the most investigated operations among retroperitoneal laparoscopic operations. Advantages of laparoscopic adrenalectomy could be described as decreased operative blood loss, reduced narcotic requirements, and shorter hospital stay and recovery time have been reported in small series (Gagner et al, 1997). In one of the biggest series, Shen et al reported 8 conversion for 261 patients between 1993 and 2003 (Shen 
et al, 2004). Rate of conversion for adrenalectomy ranges from $0 \%$ to $5 \%$ in the literature but reasons for conversion to open adrenalectomy was studied in a few studies (Shen et al, 2004). By retrospective evaluation of 3 converted patients, it was realized that laparotomy had to be plan according to radiographic appearance or dimension of the tumor (Shen et al, 2004). Tumor adhesions to neighboring tissue were the reason of the conversions of the 3 patients (Shen et al, 2004). These cases were right-sided adrenal tumors which effected liver and vessels like inferior vena cava and right renal vein (Shen et al, 2004). Two of the 8 converted patients in Shen et al series had tumors with 15 and $16 \mathrm{~cm}$ in size that caused conversion (Shen et al, 2004). Gagner et al reported three converted patients in their series. The first patient in their report had $15 \mathrm{~cm}$ angiomyolipoma in right adrenal gland (Gagner et al, 1997). Second case had invasion to posterior muscles and third has $12 \mathrm{~cm}$ right adrenal mass (Gagner et al, 1997). Gagner et al revealed that a mass in adrenal gland larger than 15 cm might be accepted as contraindication for laparoscopy (Gagner et al, 1997). It was also reported that metastatic nodes in the periaortic chain or close to the bladder detected by magnetic resonance imaging or metaiodobenzylguanidine nuclear scan desires open technique rather than laparoscopy (Gagner et al, 1997).

Shanberg et al reported that right-sided retroperitoneal laparoscopic adrenalectomy was difficult to accomplish. Right adrenal vein and the inferior vena cava were the main reasons of limitation of the process (Shanberg et al, 2001).

\section{Inappropriate circumstances for anesthesia}

The reports about the problems related to anesthesia as a reason of conversion of the laparoscopic procedures to laparotomy were very few (Cunningham, 1998). The reason of this situation may originate from the lower incidence of anesthesia-related complications during laparoscopy (Girish, 2001). Usually, case dependent reports were presented and most of them were determined in the surgical series. However, careful evaluations give clues in finding out some issues that can be accepted as predictors for anesthesia related conversion.

Bleeding is an important aspect for conversion. For patients with cirrhosis laparoscopy and open procedure has risks of bleeding (Delis et al, 2010). Delis et al reported 12 cases that had to be converted and five of 12 had bleeding problems (Delis et al, 2010). For these patients, MELD scorring system is used for predicting the rates of the conversions in their study and all these patients had higher scores before operations (Delis et al, 2010). One of the fields MELD scorring system is used for the evaluation of the postoperative outcome of the cirrhotic patients (Delis et al, 2010). MELD score included three laboratory test measured preoperatively: international normalized ratio (INR), serum total bilirubin (TBil), and serum creatinine $(\mathrm{Cr})$ and was calculated using the following formula: MELD $=9.57 \times \log _{\mathrm{e}}(\mathrm{Cr}$ $\mathrm{mg} / \mathrm{dL})+3.78 \times \log _{\mathrm{e}}(\mathrm{TBil} \mathrm{mg} / \mathrm{dL})+11.20 \times \log _{\mathrm{e}}(\mathrm{INR})+6.43$ (Delis et al, 2010). Median MELD scores of these patients was 15 (range 11-22) described in their study and higher conversion rate was noted in patients with MELD score above 13 (Delis et al, 2010). Bleeding consists in special feature for spleen operations. Brody et al reported two patients affected from the bleeding (Brody et al, 1999). These patients had less than 50,000 $\mathrm{mm}^{-3}$ platelet counts and intraoperative oozing was detected (Brody et al, 1999). Authors figured out that patients with ITP and platelet counts less than 50,000 $\mathrm{mm}^{-3}$ undergo a preoperative bleeding time for assessment of qualitative clotting capabilities (Brody et al, 1999). It was reported 
that early ligation of splenic artery through lesser sac and platelet infusion with adjunctive blood products might be suitable to interfere bleeding and to prevent the patient from conversion (Brody et al, 1999).

Pre-existing chronic obstructive and restrictive lung diseases may have challenges in laparoscopy. Hypoxemia and respiratory acidosis was documented in recent studies (Cunningham, 1998). Brody et al reported a conversion of chronic obstructive pulmonary disease (COPD) patient secondary to an extensive smoking history complicated by nocardia pneumonitis 3 months before operative intervention (Brody et al, 1999).

Intraperitoneal carbon dioxide $\left(\mathrm{CO}_{2}\right)$ insufflation and changes in patient positioning might cause hemodynamic, pulmonary, and endocrine problems (Girish, 2001). Alterations in arterial blood pressure (i.e., hypotension and hypertension), dysrhythmias, and cardiac arrest are some of the major hemodynamic complications (Girish, 2001). Bradyarrhythmias, atrioventricular dissociation, nodal rhythm, and asystole have been reported and the incidence of dysrhythmias during laparoscopy is found to be approximately $14 \%$ (Girish, 2001). Reissman \& Spira reported that gas insufflation may cause altering in the cardiac output and compress the femoral veins but conversions because of this mechanism are not clear (Reissman \& Spira, 2003). In a study significant cardiac performance decrease was shown after peritoneal insufflation during laparoscopic procedures especially in young patients who were operated for gynecological diseases (Harris et al, 1996). Harris et al reported that cardiovascular collapse was experienced in their patients (Harris et al, 1996). Kathouda et al reported 2 conversions for their intestine perforation operations because of cardiovascular instability (Kathouda et al, 1996).

Significant hypoxemia and hypercapnia are the major pulmonary complications during laparoscopy particularly in patients with severe pulmonary disease and limited elimination of $\mathrm{CO}_{2}$ (Girish, 2001). $\mathrm{ETCO}_{2}$ levels might not correlate with arterial $\mathrm{CO}_{2}$ concentrations in these patients (Girish, 2001). Bhayani et al reported that two cases were converted because of hypercarbia that was unresponsive to hyperventilation and lowering of carbon dioxide gas insufflation (Bhayani et al, 2004). They treated patients with hypercarbia by increasing the minute ventilation and lowering the insufflation pressure. Bhayani et al warned surgeon and anesthesiologist for proper communication during operation against hypercarbia situations (Bhayani et al, 2004). Bhayani et al suggested conversions if hypercarbia continue in spite of hyperventilation and lowering insufflation (Bhayani et al, 2004). However increased risk of lung injury owing to increase in alveolar pressures has to be recognized particularly in patients with extensive pulmonary disease (Girish, 2001). Getting ready for possible problems, preoperative pulmonary functions and arterial blood gas analysis may be performed in significant dysfunctioning patient group (Girish, 2001). If laparoscopy is performed, operation would better be monitored by a radial artery cannula for arterial blood gas analysis (Girish, 2001).

Gas embolism might be important that could be observed with precordial Doppler gynecologic laparoscopic procedures but of the patients' evaluated, $69 \% \mathrm{CO}_{2}$ embolism diagnosed by transesophageal echocardiography for laparoscopic cholecystectomy procedures without significant cardiopulmonary changes (Girish, 2001). Six percent of patients undergoing laparoscopic nephrectomy had gas embolisms detected by transesophageal echocardiography (Girish, 2001). Clinical importance has not been detected yet. 
Obesity is another factor that had to be recognized by anesthesiologist. Conversion rates vary from $14 \%$ to $36 \%$ compared with $5 \%$ to $6 \%$ in non-obese patients, depending on the type of and indication for surgery. (Lamvu et al, 2004). Simopoluos et al described obesity as a risky and hazardous factor for conversion to open cholecystectomy (Simopoluos et al, 2005). Body mass index (BMI) is important for conversion. Tekkis et al reported high rates of conversions with high BMI undergoing low pelvic surgery or left-sided colectomy. As predictors of conversion, shown in multivariate analysis, ASA grade, BMI, type of surgery, intraabdominal abscess, or fistula, and surgeon seniority has to be recognized (Tekkis et al, 2005). Suter et al reported two converted patients who were operated for small bowel obstruction (Suter et al, 2000). These patients were in ASA 4 risk category and one of them was an 80-year-old alcoholic patient with liver cirrhosis and the other one was a 53-year-old man with coronary heart disease (Suter et al, 2000).

There is a controversy for the conversions due to diabetes mellitus but Simopoluos et al reported the possibility of conversion of diabetic patients might occur for the presence of acute inflammation or changes in the wall from microvascular diseases (Simopoluos et al, 2005).

Among medications steroids were shown to be related with conversion to an open procedure (Schmidt et al, 2001). This could be accepted as an important side effect of the drug. Association of steroids, being malnourished and smoking made the conversion risk higher (Schmidt et al, 2001). Schmidt et al explain this association of the factors as the severity of the patients 'disease which subsequently hardens the operation itself (Schmidt et al, 2001).

There were demographic studies about the affect of gender on conversions (Simopoluos et al, 2005). Some authors reported male gender has a correlation whereas some does not agree with it (Simopoluos et al, 2005). It was also added by the authors that the reason of the prediction of gender was unclear.

\section{Conclusion}

Looking over the picture of laparoscopy, it can easily be said that expansion of the usage, indications and accesses is in a positive trend and in a fast motion. Therefore, it will not be surprising to foresee a significant decrease in the contraindication parameters in a near future. During this expansion and progression of laparoscopic procedures, literature has already begun to enhance its' difficulties, complications and conversions. According to many authors, conversions may give suitable clues for the better and easier operations, but if they are taken into account. For this reason, many reports defined conversions in all types of laparoscopic operations. Conversion, as it is figured out in literature, elongated the healing time, hospital stay and perhaps added new complications in the therapy process of the patient. Discouragement and disappointment is another dimension of the problem, as the result arise totally different from preoperative planning of the surgeon and patient because of the conversion.

So, voting out laparoscopy or completing the laparoscopy plan in success is one of the main goals in laparoscopic surgeries. For this purpose, problems interrupting laparoscopy have to be known. Definition of predicting factors of conversions are important at this point. Authors put forward previous operations to make standard definitions of predicting factors 
but consensus has not been maintained. Some strong predictors that all the authors agree with, consists in different parameters in details which causes controversies. Although, predicting factors like adhesions, obesity, unclear anatomy, bleeding, hypercarbia, tumor size have been figure out, it is hard to say that systematized way of decision-making has been structured by the authors that reported these predictors.

Another problem is insufficient demonstration of the reasons for conversion. By evaluating the literature of conversion for the sake of clear planning of operations, we can say that the missing part of the reports is the precise definition of the conversion reasons. This interrupts the accumulation of the knowledge. Exact and objective definitions of reasons will stimulate the accumulation of the useful information and conversion reasons will be classified after this. As a result, authors will easily understand the patients' potential conversion. Thus, it will be better to define the exact situation of the conversion reasons with measurable criteria and putting forward the exact differences of the converted patient from completed laparoscopies.

In the next step, it will be important to evaluate the diagnostic tools, invented or augmenting instruments, either laboratory or radiological, to foresee a conversion reason and to figure out the predicting factor. Usage of some diagnostic tools and laboratory instruments are reported in this chapter for this reason although it is not sufficient.

Having the data consisting in descriptions and diagnostic evaluations, one can successfully review the decision-making algorithm and may structure it in details for successful plan. We can speculate that diagnostic tools predicting the conversions may ease the surgeons' decisions and patients' expectations for healing in a schedule. Finally, we also speculate that it is time to configure international study groups for conversion investigations to organize all these data, diagnostic tools.

\section{References}

Agresta,F.; De Simone, P., Bedin, N. (2004). The Laparoscopic Approach in Abdominal Emergencies: A Single-Center 10-Year Experience. Journal of the Society of Laparoendoscopic Surgeons 8, 25-30, ISSN 1086-8089

Akyurek, N.: Salman, B., Irkorucu, O., Tascilar, O., Yuksel, O, Sare, M. \& Tatlicioglu, M. (2005). Laparoscopic Cholecystectomy in Patients With Previous Abdominal Surgery. Journal of the Society of Laparoendoscopic Surgeons. 9,178-183, ISSN 1086-8089

Atchabahian, A.; Lasinu, M.J., Riche, F., Briard, C. \& Nemeth J, V. (1996). Small Bowel Fistulae in Degos' Disease: A Case Report and Literature Review. The American J of Gastroenterol 91, 2208-11, ISSN 0002-9270

Ball,C. G.; Kortbeek, J. B., Kirkpatrick, A. W. \& Mitchell, P. (2004). Laparoscopic appendectomy for complicated appendicitis An evaluation of postoperative factors. Surg Endosc 18, 969-973, ISSN 0930-2794

Bhayani, S. B.; Pavlovich, C.P., Strup, S.E., Dahl, D. M., Landman, J., Fabrizio, M. D. Sundaram, C.P., Kaouk, J. H. \& Li-Ming, S. (2004). Laparoscopic Radical Prostatectomy: A Multi-Institutional Study Of Conversion To Open Surgery. Urology 63, 99-102, ISSN 0090-4295 
Brody, F. J.; Chekan, E. G., Pappas, T. N. \& Eubanks, W. S. (1999). Conversion factors for Laparoscopic splenectomy for immune thrombocytopenic purpura. Surg Endosc 13, 789-791, ISSN 0930-2794

Chelala,E. ; Cadie're, G. B. , Favretti, F. , Himpens, J., Vertruyen, M., Bruyns, J., Maroquin,L. \& Lise, M. (1997). Conversions and complications in 185 laparoscopic adjustable siliconegastric banding cases. Surg Endosc 11, 268-271, ISSN 0930-2794

Cherqui, D.; Husson, E., Hammoud, R., Malassagne, B., Stephan, F., Bensaid, S., Rotman, N. \& Fagniez, P.(2000). Laparoscopic Liver Resections: A Feasibility Study in 30 Patients. Annals of Surgery. 232, 753-762, ISSN 0003-4932

Chi, D. S.; Abu-Rustum, N.R., Sonoda , Y., Awtrey, C., Hummer, A., Venkatraman, E. S., Franklin, C.C., Hamilton, F., Gemignani, M.L. \& Barakat, R. R. (2004). Ten-year experience with laparoscopy on a gynecologic oncology service: Analysis of risk factors for complications and conversion to laparotomy. American Journal of Obstetrics and Gynecology 191, 1138-45, ISSN 0002-9378

Chung,R. S. ; Diaz, J. J. \& Chari, V.(1998). Efficacy of Routine laparoscopy for the acute abdomen Surg Endosc 12, 219-22, ISSN 0930-2794

Cucinotta, E.; Lazzara, S. \& Melita, G. (2003). Laparoscopic cholecystectomy in cirrhotic patients. Surg Endosc 17,1958-1960, ISSN 0930-2794

Cunningham, A. J. (1998). Anesthetic Implications of Laparoscopic Surgery. Yale Journal Of Biology And Medicine Vol 71, pp. 551-578, ISSN 0044-0086

Dagher,I.; Proske, J. M., Carloni, A., Richa, H., Tranchart, H., Franco, D. (2007). Laparoscopic liver resection: results for 70 patients. Surg Endosc 21, 619-624, ISSN 0930-2794

Delis, S.; Bakoyiannis, A., Madariaga, J., Bramis, J., Tassopoulos, N. \& Dervenis,C. (2010). Laparoscopic cholecystectomy in cirrhotic patients: the value of MELD score and Child-Pugh classification in predicting outcome. Surg Endosc 24. 407-412, ISSN 0930-2794

Dubuisson, J.B.; Fauconnier, A., Fourchotte, V., Babaki-Fard, K., Coste, J. \& Chapron, C. (2001). Laparoscopic myomectomy: predicting the risk of conversion to an open procedure. Human Reproduction 16, 1726-1731, ISSN 0268-1161

El-Ghoneimi, A.; Farhat, W., Bolduc, S., Bagli, D., Mclorie, G., Aigrain, Y. \& Khoury, A.(2003). Laparoscopic dismembered pyeloplasty by a retroperitoneal approach in children. BJU International 92, 104-108, ISSN 2042-2997

Esposito,C. ; Ascione, G. , Garipoli, V., De Bernardo, G. \& Esposito, G. (1997). Complications of pediatric laparoscopic surgery. Surg Endosc 11, 655-657. ISSN 0930-2794

Fergany, A.F.; Novick, A.C. \& Gill, I.S.(2000). Laparoscopic urinary diversion. World J Urol 18, 345-348, ISSN 0724-4983

Floch,N. R.; Hinder, R. A. , Klingler, P. J. , Branton, S. A., Seelig, M.H., Bammer, T. \& Filipi, C.J. (1999). Is Laparoscopic Reoperation for Failed Antireflux Surgery Feasible? Arch Surg 134, 733-737, ISSN 0004-0010 
Fong, Y.; Jarnagin, W., Conlon, K. C. , DeMatteo, R., Dougherty, E. \& Blumgart, L.H. (2000).Hand-Assisted Laparoscopic Liver Resection Lessons From an Initial Experience. Arch Surg 135, 854-859, ISSN 0004-0010

Gagner, M.; Pomp, A., Heniford, B. T., Pharand, D. \& Lacroix, A. (1997). Laparoscopic Adrenalectomy Lessons Learned From 100 Consecutive Procedures. Annals Of Surgery 226, 238-247. ISSN 0003-4932

Girish, P.J.(2001). Complications of Laparoscopy. Anesthesiology Clinics of North America 19, 89-105, ISSN 0889-8537

Glasgow, R. E.; Yee, L. F. \& Mulvihill S. J. (1997). Laparoscopic splenectomy The emerging standard. Surg Endosc 11, 108-112. ISSN 0930-2794

Hansen, A. J. ; Tessier, D. J., Anderson, M. L. \& Schlinkert, R. T. (2007). Laparoscopic Repair of Colonoscopic Perforations:Indications and Guidelines. J Gastrointest Surg 11,65559, ISSN 1091-255X

Harris, S.N.; Ballantyne, G.H., Luther, M. A. \& Perrino, A.C.Jr. (1996). Alterations of Cardiovascular Performance During Laparoscopic Colectomy: A Combined Hemodynamic and Echocardiographic Analysis. Anesth Analg 83,482-7, ISSN 00032999

Higa, K. D.; Boone, K.B. \& Ho, T. (2000). Complications of the Laparoscopic Roux-en-Y Gastric Bypass: 1,040 Patients - What Have We Learned? Obesity Surgery 10, 509- 13, ISSN 0960-8923

Jansen, F.W.; Kapiteyn, K., Trimbos-Kemper, T., Hermans, J.\& Trimbos, J.B. (1997). Complications of laparoscopy:a prospective multicentre observational study. British Journal of Obstetrics and Gynaecology, Vol 104, pp.595-600. ISSN 14700328

Jaroszewski, D. E.; Schlinkert, R. T., Thompson, G. B., Schlinkert, D. K. (2004). Laparoscopic Localization and Resection of Insulinomas. Arch Surg 139, 270-274, ISSN 0004-0010

Karayiannakis, A. J.; Polychronidis, A., Perente, S., Botaitis, S., Simopoulos, C. (2004). Laparoscopic cholecystectomy in patients with previous upper or lower abdominal Surgery. Surg Endosc 18, 97-101. ISSN 0930-2794

Katkhouda, N.; Waldrep, D., Feinstein, D., Soliman, H., Stain, S.C., Ortega, A.E. \& Mouiel, J. (1996). Am J Surg 172, 585-590, ISSN 0002-9610

Keeley, F.X. \& Tolley, D.A. (1998). A Review of our first 100 cases of laparoscopic nephrectomy:defining risk factors for complications. BJU 82, 615-618, ISSN 00071331

Kwok, S. P. Y. ; Lau, W. Y. , Declan Carey, P., Kelly, S. B., Leung, K. L. \& Li, A. K. C. (1996). Prospective Evaluation of Laparoscopic-Assisted Large-Bowel Excision for Cancer. Annals of Surgery 223, 170-176. ISSN 0003-4932

Lamvu,G.; Zolnoun, D., Boggess, J. \& Steege, J. F. (2004). Obesity: Physiologic changes and challenges during laparoscopy. American Journal of Obstetrics and Gynecology 191, 669-74, ISSN 0002-9378

Le Moine, M. C.; Fabre, J.M., Vacher, C., Navarro, F., Picot, M.C. \& Domergue, J.(2003). Factors and consequences of conversion in laparoscopic sigmoidectomy 
for diverticular disease. British Journal of Surgery 90, 232-236, ISSN 00071373

Mahon, D. \& Rhodes, M. (2003).Laparoscopic splenectomy: size matters Ann R Coll Surg Engl. 85,248-251, ISSN 0035-8843

Marusch, F.; Gastinger, I., Schneider, C., Scheidbach, H., Konradt, J., Bruch, H.P., Köhler, L., Barlehner, E., Köckerling, F. \&Laparoscopic Colorectal Surgery Study Group (LCSSG).(2001). Importance of Conversion for Results Obtained with Laparoscopic Colorectal Surgery. Dis Colon Rectum 44, 207-216, ISSN 00123706

Matın, S.F. (2005). Radical laparoscopic nephroureterectomy for upper urinary tract transitional cell carcinoma: current status. BJU International 95, Suppl 2 , 68-74, ISSN 2042-2997

Mendoza, D.; Newman, R.C., Albala, D., Cohen, M.S., Tewari, A., Lingeman, J., Wong, M., Kavoussi, L., Adams, J., Moore, R., Winfiled, H., Glascock, M., Das, S., Munch, L., Grasso, M., Dickinson, M., Clayman, R., Nakada, S., McDougall, E.M., Wolf, S., Hulbert, J., Leveillee, R.J., Houshair, A. \& Carson, C. (1996). Laparoscopic complications in markedly obese urologic patients (A multi-instutional review). Urology 48, 562-567, ISSN 0090-4295

Moreno, G.S.; Shmookler, B.M. \& Sugarbaker, P.H. (1998). Appendiceal mucocele. Surg Endosc 12, 1177-1179, ISSN 0930-2794

Poddoubnyi, I.V.; Dronov, A.F., Blinnikov, O.I., Smirnov, A.N., Darenkov, I.A. \& Dedov, K.A. (1998). Laparoscopy in the treatment of Intussusception in Children. J Pediatr Surg 33, 1194-1197, ISSN 0022-3468

Reissman, P. \& Spira, R.M. (2003). Laparoscopy for Adhesions. Seminars in Laparoscopic Surgery Vol 10, pp 185-190. ISSN 1071-5517

Sagiv, R.; Golan, A. \& Glezerman, M. (2005).Laparoscopic Management of Extremely Large Ovarian Cysts. Obstet Gynecol 105, 1319 -22, ISSN 0029-7844

Santala, M.; Jarvela, I. \& Kauppila, A.(1999). Transfundal insertion of a Veress needle in laparoscopy of obese subjects: a practical alternative. Human Reproduction 14,2277278, ISSN 0268-1161

Santambrogio, R.; Opocher, E., Pisani Ceretti, A., Barabino, M., Costa, M., Leone, S., Montorsi, M. (2007). Impact of intraoperative ultrasonography in laparoscopic liver surgery Surg Endosc 21, 181-188. ISSN 0930-2794

Schmidt, C. M.; Talamini, M.A., Kaufman, H.S., Lilliemoe,K.D., Learn, P. \& Bayless, T. (2001). Laparoscopic Surgery for Crohn's Disease: Reasons for Conversion. Annals of Surgery 233, 733-739. ISSN 0003-4932

Shanberg, A.M.; Snaderson, K., Rajpoot, D. \& Duel, B. (2001). Laparoscopic retroperitoneal renal and adrenal surgery in children. BJU International 87, 521-524, ISSN 2042 2997

Shea, J. A.; Healey, M. J., Berlin, J. A., Clarke, J. R., Malet, P. F., .Staroscik ,R. N., Schwartz, J. S. \& Williams, S.V.(2004). Mortality and Complications Associated with Laparoscopic Cholecystectomy A Meta-Analysis. Annals of Surgery Vol. 224, 609- 20, ISSN 0003-4932 
Shen, W. T.; Kebebew, E., Clark, O.H. \& Duh, Q.Y. (2004). Reasons for Conversion from Laparoscopic to Open or Hand-assisted Adrenalectomy: Review of 261 Laparoscopic Adrenalectomies from 1993 to 2003. World J.Surg 28, 1176-1179, ISSN 0724-4983

Simopoulos, C.; Botaitis, S., Polychronidis, A., Tripsianis, G. \& Karayiannakis, A. J. (2005). Risk factors for conversion of laparoscopic cholecystectomy to open cholecystectomy. Surg Endosc 19: 905-909. ISSN 0930-2794

Sitsen,E.; Bax, N. M. A. \& van der Zee D. C.(1998). Is laparoscopic pyloromyotomy superior to open surgery? Surg Endosc 12, 813-815. ISSN 0930-2794

Siu, W. T.; Chau, C.H., Law, B. K. B., Tang, C.N., Ha, P. Y. \& Li, M. K. W. (2004). Routine use of laparoscopic repair for perforated peptic ulcer British Journal of Surgery 91, 481-484. ISSN 0007-1373

Smith, E. B.(1992). Complications of laparoscopic cholecystectomy. Journal of the National Medical Association 84, 880-882, ISSN 0027-9684

So, J.B.Y.; Chiong, E.C., Chiong, E., Cheah, W.K., Lomanto, D., Goh, P. \& Kum, C.K.(2002). Laparoscopic Appendectomy for Perforated Appendicitis. World J Surg 26, 14851488 .

Soot, S. J.; Eshraghi, N., Farahmand, M., Sheppard, B. C. \& Deveney, C.W. (1999). Transition From Open to Laparoscopic Fundoplication The Learning Curve. Arch Surg 134, 278-281, ISSN 0004-0010

Strickland, P.; Lourie, D. J., Suddleson, E. A., Blitz, J. B. \& Stain, S. C. (1999). Is laparoscopy safe and effective for treatment of acute small-bowel obstruction? Surg Endosc 13, 695-698. ISSN 0930-2794

Suter, M.; Zermatten, P., Halkic, N., Martinet, O. \& Bettschart V. (2000). Laparoscopic management of mechanical small bowel obstruction Are there predictors of success or failure? Surg Endosc 14, 478-483. ISSN 0930-2794

Szomstein, S.; Lo Menzo, E., Simpfendorfer, C., Zundel, N., Rosenthal, R.J.(2006). Laparoscopic Lysis of Adhesions. World J Surg 30, 535-540. ISSN 0724-4983

Targarona, E. M. ; Espert, J. J., Balagu, C., Piulachs, J., Artigas, V. \& Trias, M. (1998). Splenomegaly Should Not Be Considered a Contraindication for Laparoscopic Splenectomy. Annals of Surgery Vol. 228, 35-39. ISSN 0003-4932

Tekkis, P. P.; Senagore, A.J. \& Delaney, C. P. (2005). Conversion rates in laparoscopic colorectal surgery A predictive model with 1253 patients. Surg Endosc 19: 47-54. ISSN 0930-2794

Villavicencio, R.T. \& Aucar, J.A. (1999). Analysis of Laparoscopy in Trauma. J Am Coll Surg 189, 11-20, ISSN 1072- 7515

Walker, J. L.; Piedmonte, M. R., Spirtos, N. M., Eisenkop, S. M., Schlaerth, J. B., Mannel, R. S., Spiegel, G., Barakat, R., Pearl, M. L. \& Sharma, S.K.(2009). Laparoscopy Compared With Laparotomy for Comprehensive Surgical Staging of Uterine Cancer: Gynecologic Oncology Group Study LAP2. J Clin Oncol 27, 5331-5336, ISSN 0732183X

Wullstein, C. \& Gross, E. (2003). Laparoscopic compared with conventional treatment of acute adhesive small bowel obstruction British Journal of Surgery 90, 1147-1151, ISSN 0007-1373 
Yun, S. S.; Hwang, D. W., Kim, S. W., Park, S.H., Park, S. J., Lee, D. S. \& Kim, H. J. (2010) Better Treatment Strategies forPatients with Acute Cholecystitis and American Society of Anesthesiologists Classification 3 or Greater.Yonsei Med J 51:540-545, ISSN 0513-5796 


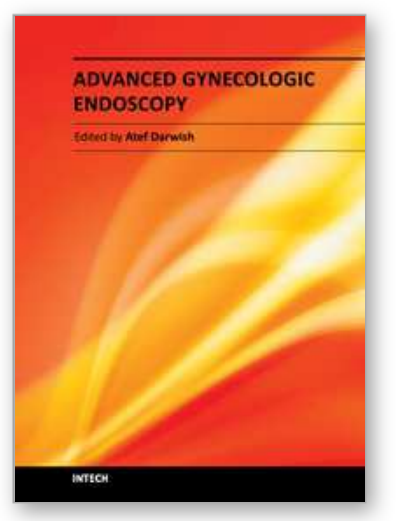

\author{
Advanced Gynecologic Endoscopy \\ Edited by Dr. Atef Darwish
}

ISBN 978-953-307-348-4

Hard cover, 332 pages

Publisher InTech

Published online 23, August, 2011

Published in print edition August, 2011

The main purpose of this book is to address some important issues related to gynecologic laparoscopy. Since the early breakthroughs by its pioneers, laparoscopic gynecologic surgery has gained popularity due to developments in illumination and instrumentation that led to the emergence of laparoscopy in the late 1980's as a credible diagnostic as well as therapeutic intervention. This book is unique in that it will review common, useful information about certain laparoscopic procedures, including technique and instruments, and then discuss common difficulties faced during each operation. We also discuss the uncommon and occasionally even anecdotal cases and the safest ways to deal with them. We are honored to have had a group of world experts in laparoscopic gynecologic surgery valuably contribute to our book.

\title{
How to reference
}

In order to correctly reference this scholarly work, feel free to copy and paste the following:

Atilla Şenaylı and Yeşim Şenaylı (2011). Inappropriate Circumstances for Laparoscopic Surgery, Advanced Gynecologic Endoscopy, Dr. Atef Darwish (Ed.), ISBN: 978-953-307-348-4, InTech, Available from: http://www.intechopen.com/books/advanced-gynecologic-endoscopy/inappropriate-circumstances-forlaparoscopic-surgery

\section{INTECH}

open science | open minds

\section{InTech Europe}

University Campus STeP Ri

Slavka Krautzeka 83/A

51000 Rijeka, Croatia

Phone: +385 (51) 770447

Fax: +385 (51) 686166

www.intechopen.com

\section{InTech China}

Unit 405, Office Block, Hotel Equatorial Shanghai

No.65, Yan An Road (West), Shanghai, 200040, China

中国上海市延安西路65号上海国际贵都大饭店办公楼 405 单元

Phone: $+86-21-62489820$

Fax: +86-21-62489821 
(C) 2011 The Author(s). Licensee IntechOpen. This chapter is distributed under the terms of the Creative Commons Attribution-NonCommercialShareAlike-3.0 License, which permits use, distribution and reproduction for non-commercial purposes, provided the original is properly cited and derivative works building on this content are distributed under the same license. 